\title{
Significance of tomographic signs in the diagnosis of bronchial carcinoma
}

\author{
M J TURNER, A S C THORNTON, B GORMAN, L R BAGG, I D COX, \\ N J RUSSELL \\ From the Departments of Thoracic Medicine and Radiology, London Hospital (Whitechapel), London
}

\begin{abstract}
In a previous study the value of conventional tomography was assessed in the diagnosis of 100 potentially malignant opacities on the chest radiograph. To determine which of the radiological signs were most useful the radiologists reviewed 82 of the original 100 radiographs independently, searching for the presence or absence of 36 signs. The five commonest signs of bronchial carcinoma were a mass, coarse linear shadows contiguous to a mass, unilateral hilar enlargement, linear shadows from mass to periphery, and an irregular margin to a mass. The combination of either two or three of these signs was highly sensitive, $95 \%$ and $89 \%$ respectively, in detecting carcinoma. The most useful specific signs were lobulation of the mass and cavitation with thick or irregular walls.
\end{abstract}

In a previous paper we compared conventional linear tomography with fibreoptic bronchoscopy in the diagnosis of potentially malignant chest opacities in 100 patients. ${ }^{1}$ We found that tomography had an accuracy of $83 \%$, sensitivity $92 \%$ and specificity $58 \%$, whereas bronchoscopy had an accuracy of $76 \%$, sensitivity $68 \%$ and specificity $100 \%$. In that study three radiologists examined the tomograms and radiographs jointly and gave a majority diagnosis in each case, based on 8 radiological signs regarded as being suspicious of malignancy. ${ }^{1}$ The same three radiologists have now reviewed 82 of the same tomograms and radiographs to determine the presence or absence of 36 radiological signs, including the original 8.

\section{Methods}

CRITERIA

Thirty six radiological signs were sought in each case (appendix), the additions to the original eight being suggested from the experience of the former study.

\section{PATIENTS}

All the patients had a localised abnormality on their chest radiograph and were referred to confirm or exclude a diagnosis of carcinoma. In the original study there were 74 patients with bronchial car-

Address for reprint requests: Dr M J Turner, Alexandra Wing X Ray Department, London Hospital, Whitechapel, London El IBB. cinoma and 26 with benign lesions, but only 82 of the original records were accessible for review. Of these, 61 patients $(74 \%)$ had bronchial carcinoma and 21 $(26 \%)$ a benign lesion, preserving the original ratio exactly. The benign diagnoses were predominantly inflammatory conditions or scarring. The original tomograms and radiographs of these 82 patients were re-examined by each of the three radiologists (AT, BG, and MT) without consultation, and the presence or absence of each radiological sign was recorded. A sign was subsequently regarded as being present when detected by at least two observers. If found by only one observer it was considered to be absent. No attempt was made to reach a diagnosis on this review. Our definitions were:

$$
\begin{aligned}
& \text { Sensitivity }=\frac{T P}{T P+F N} \\
& \text { Specificity }=\frac{T N}{T N+F P},
\end{aligned}
$$

where $\mathrm{TP}=$ true positive, $\mathrm{FN}=$ false negative, $\mathrm{TN}$ $=$ true negative, and $\mathrm{FP}=$ false positive.

\section{Results}

The radiological signs of malignancy in descending order of specificity and sensitivity are shown in tables 1 and 2. Values below $60 \%$ are omitted. The definition of sensitivity used is identical to the frequency of the sign in those with malignant disease. The frequencies of the 36 signs in carcinoma and benign disease are given in the appendix. 
Table 1 Radiological signs of malignancy placed in order of highest specificity

\begin{tabular}{|c|c|c|c|c|}
\hline $\begin{array}{l}\text { Rank } \\
\text { order }\end{array}$ & $N o^{*}$ & Radiological sign & $\begin{array}{l}\text { Specificity (\%) } \\
\left(\frac{T N}{T N+F P}\right)\end{array}$ & $\begin{array}{l}\text { Sensitivity (\% } \\
\left(\frac{T P}{T P+F N}\right)\end{array}$ \\
\hline $\begin{array}{r}1 \\
2 \\
3 \\
4 \\
5 \\
6 \\
7 \\
8 \\
9 \\
10 \\
11\end{array}$ & $\begin{array}{r}36 \\
22 \\
8 \\
6 \\
3 \\
29 \\
18 \\
4 \\
20 \\
27 \\
21\end{array}$ & $\begin{array}{l}\text { Bone destruction (rib) } \\
\text { Linear shadows-lymphatic } \\
\text { Cavitation-wall > } 5 \mathrm{~mm} \\
\text { Cavitation-wall irregular } \\
\text { Lobulation of mass } \\
\text { Pleural effusion unilateral } \\
\text { Linear shadows contiguous to mass, fine } \\
\text { Margin of mass irregular } \\
\text { Linear shadows from mass to hilum } \\
\text { Tracheobronchial deformity } \\
\text { Linear shadows from mass to periphery }\end{array}$ & $\begin{array}{r}100 \\
100 \\
95 \\
95 \\
95 \\
76 \\
76 \\
71 \\
67 \\
62 \\
62\end{array}$ & $\begin{array}{r}3 \\
5 \\
16 \\
16 \\
49 \\
7 \\
38 \\
66 \\
54 \\
44 \\
69\end{array}$ \\
\hline
\end{tabular}

Table 2 Radiological signs of malignancy placed in order of highest sensitivity

\begin{tabular}{|c|c|c|c|c|}
\hline $\begin{array}{l}\text { Rank } \\
\text { order }\end{array}$ & $\mathrm{No}^{*}$ & Radiological sign & $\begin{array}{l}\text { Sensitivity (\%) } \\
\left(\frac{T P}{T P+F N}\right)\end{array}$ & $\begin{array}{l}\text { Specificity }(0 \\
\left(\frac{T N}{T N+F P}\right)\end{array}$ \\
\hline $\begin{array}{l}1 \\
2 \\
3 \\
4 \\
5\end{array}$ & $\begin{array}{r}1 \\
19 \\
25 \\
21 \\
4\end{array}$ & $\begin{array}{l}\text { Mass } \\
\text { Linear shadows contiguous to mass, coarse } \\
\text { Unilateral hilar enlargement } \\
\text { Linear shadows from mass to periphery } \\
\text { Margin of mass irregular }\end{array}$ & $\begin{array}{l}97 \\
84 \\
72 \\
69 \\
66\end{array}$ & $\begin{array}{l}33 \\
48 \\
52 \\
62 \\
71\end{array}$ \\
\hline
\end{tabular}

TN-true negative; FN-false negative; TP-true positive; FP-false positive.

Five signs have a specificity of $95 \%$ or more- "rib destruction" (100\%), "linear shadows-lymphatic" $(100 \%)$, "cavitation with wall thickness over $5 \mathrm{~mm}$ " $(95 \%)$, "cavitation with irregular walls" (95\%), and "lobulation of mass" $(95 \%)$. Values for sensitivity are lower, the highest being $97 \%$ for "mass" and $84 \%$ for "linear shadows contiguous to mass, coarse".

\section{Discussion}

\section{CONTRIBUTION OF THE RADIOLOGICAL SIGNS TO DIAGNOSIS}

At first these results may appear to contradict our previous finding that tomography has a high sensitivity and a low specificity. ${ }^{1}$ The five signs with a high specificity, however, occurred mostly at low frequency; the frequency of the highest ("lobulation") was $49 \%$, whereas the next two ("cavitation with wall thickness over $5 \mathrm{~mm}$ " and "cavitation with irregular walls") occurred only in $16 \%$. The other two signs had frequencies of only $5 \%$ and $3 \%$. Consequently, despite the impressively high specificity of these five signs, their contribution to the overall performance of tomography was relatively low.

For high sensitivity a test requires a recognisable feature common to a high proportion of positive cases. Although a single radiological sign may be unsuitable, a battery of signs can achieve the require $\bar{b}$ characteristics. The five most frequent signs in bron chial carcinoma (table 2) were "mass" (97\%), "lineab shadows contiguous to mass, coarse" (84\%), "uni lateral hilar enlargement" (72\%), "linear shadow from mass to periphery" $(69 \%)$ and "margin of mass irregular" $(66 \%)$. These five signs can be used colo lectively, to assess malignancy by the number of signs that are positive. The criterion for carcinoma may be taken arbitrarily as "two signs or more" or "three signs or more" positive. These options give sensio tivities of $95 \%$ and $89 \%$ and specificities of $38 \%$ and $57 \%$ respectively (tables 3 and 4 ). Although such battery of signs was not formally designated in the first study, a review of the original criteria ${ }^{1}$ shows thą most of them were being used and they would have contributed to the high sensitivity shown by tomos graphy. It is noteworthy that the six most common radiological signs in bronchial carcinoma-the five stated above together with "linear shadows fror $\overrightarrow{8}$ mass to hilum" (54\%)-are all closely related to th primary mass and its known pathways of direct of lymphatic spread. 
Table 3 Incidence of the five most frequent signs in malignancy (see table 2)

\begin{tabular}{lll}
\hline & No of cases & \\
\cline { 2 - 3 } $\begin{array}{l}\text { No of these signs } \\
\text { present per case }\end{array}$ & Malignant & Benign \\
\hline 5 & 24 & 4 \\
4 & 18 & 2 \\
3 & 12 & 3 \\
2 & 4 & 4 \\
1 & 1 & 4 \\
0 & 2 & 4 \\
Total & 61 & 21 \\
\hline
\end{tabular}

Table 4 Effect of using two or three of the five most frequent signs of malignancy on diagnosis of malignant and benign conditions

\begin{tabular}{lll}
\hline & $\begin{array}{l}\text { \% of malignant } \\
\text { cases detected } \\
\text { (sensitivity) }\end{array}$ & $\begin{array}{l}\text { \% of benign cases } \\
\text { misdiagnosed }\end{array}$ \\
\hline 2 or more of 5 signs & 95 & 62 \\
$\begin{array}{l}\text { positive } \\
\text { or more of 5 signs } \\
\text { positive }\end{array}$ & 89 & 43 \\
\hline
\end{tabular}

\section{SPECIFIC RADIOLOGICAL SIGNS}

\section{Air bronchogram}

We expected that "air bronchogram in mass" would be uncommon in malignancy, except in alveolar cell carcinoma or lymphoma, ${ }^{2}$ which did not occur in this series. "Air bronchogram within mass lession" was, however, found in no less than $31 \%$ of carcinomas, with majority agreement in $72 \%$, showing the sign to be of no value in excluding carcinoma. On the other hand, a recognisable bronchiectatic air bronchogram, whether near or remote from a suspect mass, occurred with only $2 \%$ of carcinomas, but was seen in $14 \%$ of benign lesions.

\section{Calcification in or near mass}

The frequency of "calcification in or within $2 \mathrm{~cm}$ of mass" was found to be $13 \%$ in carcinoma, a value much higher than the mean of about $2 \%$ quoted by several authors. ${ }^{2-4}$ Specifying a distance of less than $2 \mathrm{~cm}$ might have reduced our figure of $13 \%$ but it was difficult in practice to obtain a reasonable level of agreement between observers if smaller distances were chosen.

\section{Cavitating lesions}

Our findings concerning wall thickness and irregularity of cavitating lesions were in accord with those of Woodring et al, ${ }^{5}$ who found that over half of 65 cavities with a wall thickness of $5 \mathrm{~mm}$ or more were malignant, as were $81 \%$ of those with irregular walls.

\section{LIMITATIONS OF THIS STUDY}

Conclusions drawn from a study such as this are lim- ited in the strict sense to the sample taken. Comment about the population from which the sample is derived must be more guarded. Broadly this population represents outpatients presenting to the hospital's department of respiratory medicine with a chest radiograph suspected of showing bronchial carcinoma. In the sample under review the ratio of malignant to benign disease was about 3:1. This explains the surprisingly high specificity of unilateral pleural effusion for carcinoma in the patient population under study.

Another limitation of the survey arises from the small numbers in which some of the radiological signs were found-single figures only in the case of 13 signs, including important ones such as four pleural signs (lesion crossing pleural boundary, unilateral or bilateral pleural effusions, and extensive pleural opacity); cavitation with wall smooth or less than $5 \mathrm{~mm}$ thick; lymphatic linear shadows; bilateral hilar enlargement; and bone destruction. Some of these signs would be expected to have a different incidence in patients from different samples. Nevertheless, in our view certain helpful conclusions may be drawn about the usefulness of individual radiological signs in diagnosing bronchial carcinoma, particularly when diagnostic problems arise in connection with chest radiographic appearances in an outpatient.

We wish to thank our clinical colleagues at the London Hospital, Drs DTD Hughes, DW Empey, DM Chaput de Saintonge, and DH Trapnell, for their cooperation and encouragement. We also thank Mrs D Coram for typing the manuscript.

\section{APPENDIX: Radiological signs sought on review of tomograms and radiographs}

In the following list the percentages in parentheses represent the frequency of the sign in benign lesions and the others the frequency in carcinoma in this series.

MASS

1 Any confluent pulmonary opacity not identified as consolidation, collapse, fibrosis, oedema, or blood vessel: $97 \%(67 \%)$

\section{SHAPE OF MASS}

2 Margin smooth: $31 \%(24 \%)$

3 Margin lobulated: $49 \%(5 \%)$

4 Margin irregular: $66 \%(29 \%)$

\section{CAVITATION OF LESION}

5 Wall smooth: $2 \%(5 \%)$

6 Wall irregular: $16 \%(5 \%)$

7 Widest part of wall less than or equal to $5 \mathrm{~mm}$ : $0 \%(0 \%)$

8 Widest part of wall greater than $5 \mathrm{~mm}: 16 \%(5 \%)$ 
CALCIFICATION (other than unequivocal costal cartilage or pleural calcification)

9 In mass or within $2 \mathrm{~cm}$ of it: $13 \%(29 \%)$

10 More than $2 \mathrm{~cm}$ from mass: $7 \%(10 \%)$

11 Hilar or mediastinal calcification: $25 \%(19 \%)$

AIR BRONCHOGRAM (that is, tubular air containing structures that branch or are seen to be contiguous with the bronchus, on serial cuts if necessary)

12 In mass: $31 \%(24 \%)$

13 Distal to mass: $18 \%(14 \%)$

14 In another part of same lung: $2 \%(0 \%)$

15 Major segmental: $21 \%(29 \%)$

16 Distal segmental: $25 \%(29 \%)$

17 Bronchiectatic: 2\% (14\%)

\section{LINEAR SHADOWS}

18 Contiguous to mass, fine (less than or equal to $1 \mathrm{~mm}$ in width): $38 \%(24 \%)$

19 Contiguous to mass, coarse (greater than $1 \mathrm{~mm}$ ): $84 \%(52 \%)$

20 Extending from mass towards hilum: 54\% (33\%)

21 Extending from mass towards periphery: $69 \%$ $(38 \%)$

22 Other linear shadows characteristic of lymphatic infiltration: $5 \%(0 \%)$

23 Any other linear shadows: 5\% (19\%)

COLLAPSE

24 Lobar or segmental (other than collapse inferred from the presence of pleural effusion or consolidation): includes displacement of fissures, diaphragm, hilum, ribs, or vessels (for example, vessel crowding): $44 \%$ (43\%)

HILAR ENLARGEMENT (A local or general increase in hilar shadow not completely explicable in terms of normal structures or enlarged vessels; thus any opacity in the lung adjacent to the hilum and contiguous with it is called hilar enlargement)

25 Unilateral: $72 \%(48 \%)$

26 Bilateral: 3\% (10\%)
TRACHEAL AND BRONCHIAL DEFORMITY

27 Narrowing, deformity, or displacement of bron chi or alteration of carinal angles (affecting tra s) chea or main bronchial divisions, or main op subsidiary carina): $\mathbf{4 4 \%}(38 \%)$

28 Bronchial wall thickening - that is, with thick ened parallel lines or ring shadows (except bron: chus intermedius and right border of trachea; where evidence of one thickened wall suffices) $\vec{\omega}$ $12 \%(43 \%)$

\section{PLEURAL CHANGES}

29 Unilateral pleural effusion: $7 \%(24 \%)$

30 Bilateral pleural effusion: $2 \%(0 \%)$

31 Blunting of costophrenic angle: $23 \%(19 \%)$

32 More extensive pleural opacity: 3\% (24\%)

33 Thickening of fissures: $39 \%(43 \%)$

34 Adhesions (distortion or "tenting" of diaphragm or other structures) $12 \%$ : $(24 \%)$

35 Lesion seen to cross pleural boundary: $7 \%(0 \%$

BONE DISEASED

36 Bone destruction: $3 \%(0 \%)$

\section{References}

1 Bagg LR, Cox ID, Russell NJ, Thornton ASC, Gormana B, Turner MJ. Assessment of conventional tomo- $\frac{\mathcal{D}}{\mathbb{Q}}$ graphy and fibreoptic bronchoscopy in the diagnosis of potentially malignant chest opacities. Thoraxo 1984;39:23-7.

2 Fraser RG, Pare JAP. Diagnosis of diseases of the chest. 2nd ed. Philadelphia: WB Saunders, 1977:1055-9.

3 Felson B. Chest roentgenology. Philadelphia: WB Saunders, 1973:484-9.

4 Sutton D. ed. A textbook of radiology and imaging. 3rd ed. London: Churchill Livingstone, 1980:349.

5 Woodring JH, Fried AM, Chuang VP. Solitary cavities of the lung, diagnostic implications of cavity wall thickness. Am J Roentgenol 1980;135:1269-71. 